\title{
Self-Determination's Intrinsic Value For Post-Exile Cuban-American Women
}

\author{
Elin Cortijo-Doval, Ph.D., Virginia State University, USA \\ Christopher Doval, Esq., Virginia State University, USA \\ Mirta M. Martin Ph.D., Fort Hays State University, USA \\ Maricel Quitana-Baker, Ph.D., MQB-Consulting, Virginia, USA \\ Don Anque, J.D., California, USA
}

\begin{abstract}
This study provides insight into the role of self-determination for post Castro Cuban-American women in leadership roles in the United States. It provides a description of the dynamics and social influences that shaped, guided, and supported their self-determination skills. It outlines the process they used to achieve personal control over their lives and what empowered them to accomplish the things they perceived as important. The findings reveal the role and effect that self-determination had in how this particular group of women became leaders and how their selfdetermination stems from their passion, determination, and sense of responsibility to care and support others.
\end{abstract}

Keywords: Cuban-American; Women; Self-Determination; Leadership; Exile; Post-Exile; Post Castro; Ecological Theory; Self-Determination Theory; Empowerment

\section{INTRODUCTION}

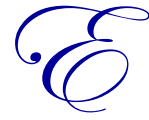

ven though they were faced with a new societal culture, Cuban men did not have to significantly adjust their previous traditional roles within the American environment, as most continued to fulfill their expected job as the main breadwinners for their families (Safar, 1995). However, for many Cuban women, their role significantly changed (Prieto, 1987). Many of these women entered the American workforce to help provide for their families, and, subsequently, became equal partners with their husbands (Prieto, 1987). With this new breadwinner identity, Cuban women were able to develop skills that were previously not available to them because of their gender, and they were able to enhance their education. They embraced their journey as empowered, self-determined, working individuals leaving behind their previous native patriarchal beliefs that a female should take a passive role in the business world (Boone, 1980). Now, years after this generation of Cuban women entered the American workforce, their footprints can be found in the development of many organizations (Garcia, 1991).

The purpose of this study is to establish a common set of traits, values and/or circumstances that led Cuban American women to embrace leadership roles. This article will outline the process they used to achieve personal control over their lives and what empowered them to accomplish the things they perceived as important.

\section{Rationale and Significance of the Study}

Research shows that within post exile Cuban culture, women have played a far more central role in their family's economic success. Despite relatively low involvement in the labor force prior to exile, Cuban women have become abundant in the work place.

It is important to study these women because their experiences and struggles have become an intricate thread in the economic tapestry of the United States (Garcia, 1991; Prieto, 1987). More importantly, studying the impact of self-determination in how these women lead and function daily will add to the body of literature that strives to impact managerial psychology by providing a wider understanding of certain aspects of human resource 
management in a global environment. Additionally, it will enrich the current resources on cultural diversity available to students and practitioners of management, psychology, and allied fields.

\section{LITERATURE REVIEW}

The role and cultural identity of women in Cuban society have changed dramatically since prerevolutionary Cuba, particularly for those expatriates who fled Castro's regime (Prieto, 1984). The severing of political, economic, and familial ties forced many to recreate their lives. Prieto's work illustrates the many difficulties and adjustments Cuban women faced when moving to the United States. Additionally, Prieto's previous works, $(1984,1987)$ evaluate the evolution of gender roles in response to the nontraditional Cuban family and the rush of values that ensue from recent immigration. Boone (1980) recounts the hardships of living with prefeminist ideologies in the ever gaining feminist cultures outside Cuba. Many female Cuban expatriates had to enter the labor force to provide economic stability, often as the sole provider for the family. This change in gender and economic roles greatly affected their psyche. Boone's case study (1989) examines these changes. While there is a body of research that addresses the relationships of Cuban women and Cuban business people during the prerevolutionary years and the 10 years following the Cuban Revolution, there needs to be more studies on the further impact of Cuban women in the American workforce.

\section{Self-Determination Theory}

This research focuses on the concept of self-determination as both a motivation (Deci \& Ryan, 1985) and as a set of skills that helps empower an individual (Wehmeyer, 1998). Through the lens of Deci and Ryan's selfdetermination motivational theory (1985), the analysis focuses on the perspective that a self-determined individual is one whose actions mirror the highest-level of self-reflection, which in turn gives them a sense of freedom to do what is intrinsically motivating and personally important to them (Deci \& Ryan, 1985). This process helps others understand the transformation of postexiled Cuban women who have embraced their ability to act without the constraints of patriarchal expectation.

The data collected for this paper was further examined from two other perspectives: First, "selfdetermination is a complex process, the ultimate goal of which is to achieve the level of personal control over life that an individual desires within those areas the individual perceives as important (Wehmeyer, Abery, Mithaug, \& Stancliffe, 2003, p. 27)" over a lifetime (Abery, 2000). This view helps explain the way in which these women took control of their personal lives to achieve what was important to them in spite of the struggles of exile and cultural challenges. Secondly, the data were examined from the perspective that self-determination is the combination of skills, knowledge, and beliefs that can empower an individual to accomplish the goals they set to achieve (Wehmeyer, 1998).

Scholars in the field of self-determination (Abery \& Stancliffe, 1996; Wehmeyer et al., 2003) suggest that not all individuals become self-determined the same way-that self-determination can be best understood when taking into consideration both the individual and the various environments in which the individual lives and that an individual develops skills through personal experiences. They also suggest Bronfrenbrenner's ecological theory (1979) as the most appropriate theory to analyze growth and development and the most effective to help decipher the influences that shape a person's self-determination (Wachs, 1999).

\section{Ecological Theory}

Bronfrenbrenner's ecological theory (1979) holds that the development of an individual is influenced by several environmental systems. It analyzes a person's development within the context of the various relationships (i.e., systems, that form a person's environment) specifically, the individuals' family, home, school, parents' work, and cultural context (e.g., cultural expectations defined by society, the national economy, socioeconomic status, etc.) (Bandura, 1986; Bronfenbrenner, 1979). This theory helps explain how individuals acquire their knowledge within a society and the structure they receive from their environment. Furthermore, the ecological theory suggest a framework that helps investigate social changes in terms of how the cumulative effect of events can affect an individual's choices (Bronfenbrenner, 1979). 
Justified by the attributes of the ecological theory, an ecological approach was used to analyze the data collected from the participants of the study. The ecological lens analyzed two perspectives: (a) the influences that shaped Cuban women's self-determination skill, and (b) how they developed their skills while emerging into selfdetermined individuals. The data were further analyzed by looking at the relationship between the various social systems with which the individuals interacted, and how each one of those systems influenced, guided, supported, and structured who they are as self-determined individuals (Bronfenbrenner, 1979).

The four social systems identified in the ecological theory were studied independently and as interrelated systems which suggest that an individual develops within the context of ecology (Bronfenbrenner, 1979, 1989):

- Microsystem: The most immediate and earliest influences are in the family, along with local neighborhood or community institutions.

- Mesosystem: The intermediate level of influences of such social institutions.

- Exosystem: The exosystem surrounds the mesosystem and refers to social settings that affect the individual but does not include them.

- Macrosystem: The most removed influences such as international, regional, or global changes.

For this study, the ecological influences of the various systems were analyzed through, but not limited to, the following lenses:

Microsystem: The schools, religious institutions, and peer groups, as well as the specific cultures with which the family identifies.

Mesosystem: The interactions between the participant's home, school, employer, and other agencies who are part of the participant's work.

Exosystem: The interaction between the participants and their workplace.

Macrosystem: The interaction with the larger cultural context that influences all the other systems. This

includes cultural values, political philosophies, exile, economic patterns, and social conditions.

\section{Theoretical Rationale}

The rationale behind using two theories is that they complement each other. How an individual acquires and develops his or her self-determination skills depends on their environment and their experiences. The selfdetermination theory was used to identify the self-determination skills the participants exercised to grow and develop, and how they used those skills: (a) as a motivational perspective, (b) gain depth of reflection to achieve the freedom to do what was intrinsically motivating and personally important to them, and (c) to achieve control over their personal lives in the pursuit of their objective. However, each individual develops in a unique way and is vitally influenced by their environment and experiences. Here is where the ecological theory helps complete the analysis. By analyzing the self-determination skills of the participants in this study through the ecological theory lenses, the cultural, social, and areas of personal interactions revealed allow us to answer the question of how and why these individuals developed their self-determination skills and were able to achieve their objectives.

\section{METHODOLOGY}

This investigation utilized a qualitative method approach with a phenomenological design. The information collected from each participant was gathered by: (a) conducting participant interviews; (b) observing the participants; (c) reviewing documents, and (d) drawing conclusions from the researchers' journal notes.

\section{Research Questions}

1. What role does self-determination play in Cuban women, particularly those who chose exile in response to Castro's occupation in 1959?

2. What experiential and environmental influences shaped what they do, how they do it, and where they do it? 


\section{Design and Methods}

A qualitative method with a phenomenological design was used to conduct this investigation. A qualitative research method involves a systematic approach where the emphasis of collecting data is more on naturally occurring phenomena and where most of the data collection is in the form of words rather than numbers (McMillan \& Schumacher, 2006). Additionally, a phenomenological design helps focus on the descriptions of people's experiences and "...how it is that they experience what they experience." ((Patton, 1999, p. 71). Furthermore, through a qualitative methods approach, significant descriptive data can be gathered from people's own written or spoken words as well as from observable behaviors (Bogdan \& Biklen, 1998). The qualitative methods that were used to collect the experiences of the women participating in this study are: (a) interviews which included an indepth demographic survey, (b) observation of participants, and (c) review of documents. In order to ensure the accuracy, triangulation methods (Taylor \& Boghan, 1998) were used to cross-validate the data collected, time periods, and the theoretical schemes of self-determination and ecological theory.

\section{Instrumentation}

\section{Interview Protocol Including Demographics}

The interview protocol was designed by a panel of experts and adapted from Wehmeyer's functional theory of self-determination (Wehmeyer et al, 2003), and Deci's self-determination scale (Deci \& Ryan, 1985a). The interview protocol adapted the content of the self-determination scales to open-ended questions to obtain more detailed information for each of the four major categories targeted by Wehmeyer-autonomy, psychological empowerment, self-regulation, and self- realization, and Deci and Ryan's psychological needs: autonomous, competence, and relatedness.

\section{Observation Protocol}

The observation protocol was designed using two information indicators: (a) self-determination Skills, and (b) the four systems of the ecological theory-Microsystem, Mesosystem, Exosystem and Macrosystem - in an effort to find the environmental influences that might have shaped the self-determination skills of the participants.

\section{Review of Documents Protocol}

To maintain structure during the review of these documents, the researcher designed a documents review protocol that targeted the recording of details pertinent to leadership and self-determination.

\section{DATA COLLECTION}

\section{Document Review}

Data collection started with the review of documents provided by the respondents. These included Vitas, resumes, and any other professional and/or personal document that the respondents voluntarily shared.

\section{Interviews}

Social conversation was used as a preamble to the interviews. This strategy helped the respondents relax and created a trusting and comfortable environment (McMillan \& Schumacher, 2006). The social conversation led naturally into the semi structured interviews. The researcher followed the structure of the interview protocol, but in some cases, other probing questions were asked to clarify the answers or to tap into another possible source of information. Simultaneous data analysis was conducted from the beginning of the collection process, and triangulation started with data collected from documents. With the accumulation of information from the reviewed documents and the interview data, the researcher was able to identify other areas for further questioning and triangulation. Also, as a closing to the interviews, the participants were invited to make last minute comments or to direct questions to the researcher. 
The interviews were conducted in person or via Skype. The interviews took place at a time mutually agreed upon between the interviewer and the respondent at their workplace.

\section{Observations}

The observations were conducted to gain knowledge about the participants' experiences as they interacted with others in their environment. The focus of the observations was to document, as observed, the roles of the participants in their own environment as they exercised self-determination skills. The information gathered from these observations was also used for triangulation purposes.

Participants' observations were defined as nonparticipatory observations. This strategy allowed the researcher to fully observe the participants' behavior while at work or in their community. It also helped the researcher observe the participant in her own environment without feeling pressured by the presence of the researcher.

Observations took place at locations and times mutually agreed upon. Each individual was observed approximately for an hour at her workplace.

\section{Procedures}

A conceptual design for the procedures of this study was developed to create structure. The design was subdivided into four stages: (a) data collection and management procedures, (b) data collection and document review, (c) data collection and interviews and observations, and (d) triangulation and emergent data/data analysis. Each stage built upon the next to facilitate an orderly and logical flow of information. As stipulated in a qualitative analysis, the procedural design that was created was not intended for execution in a strictly linear process. In practice, the researcher continuously revisited the different stages in order to clarify questions and/or themes that emerged throughout the process. The purpose of this constant rechecking was to cross-examine the data to ensure that all the leads had been followed. See Figure1- Conceptual Design for Procedures. 


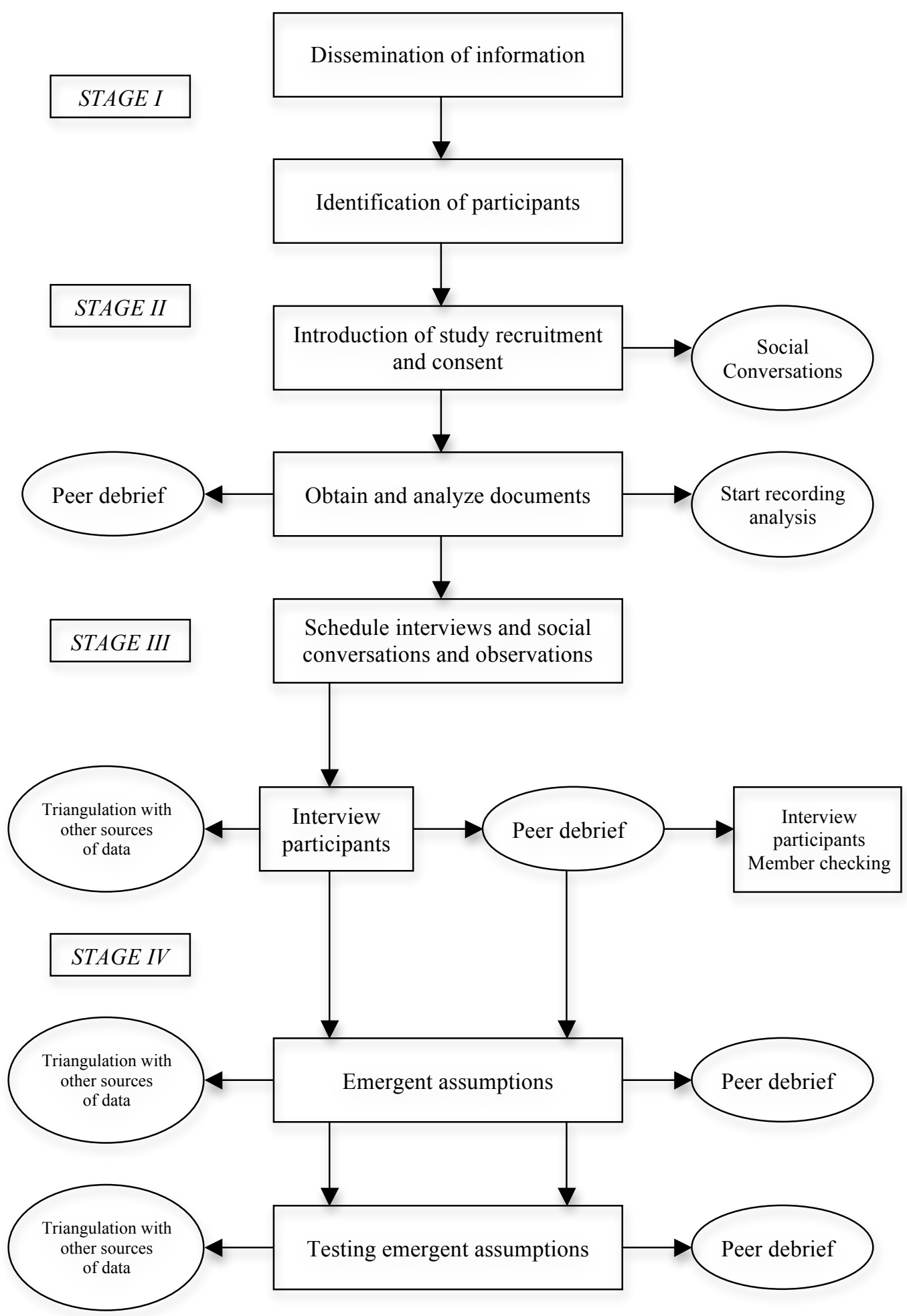

Figure 1. Conceptual Design For Procedures 


\section{Data Analysis}

A computer software program, N-VIVO, was used to organize and manage the data, and the program assisted the researcher to identify emergent themes, categories, and patterns. However, not satisfied with the reliability of this process, the researcher manually reexamined the data, completed the remaining data analysis using an audit trail, and followed a data analysis organization design created by the researcher. See figure \#2 - Data Analysis Organization Design.

Sources of data per participant: 1 . Document analysis: a) Vitae b) other documents related to the participants' work and community leadership roles; 2. Participants' interview; and 3.

Observations.

Audit trail: Raw data, field notes, and researcher's journal notes, data reduction of anylysissummaries, condense notes and tables, data re-construction and synthesis -emerging themes, and assumptions, process notes.

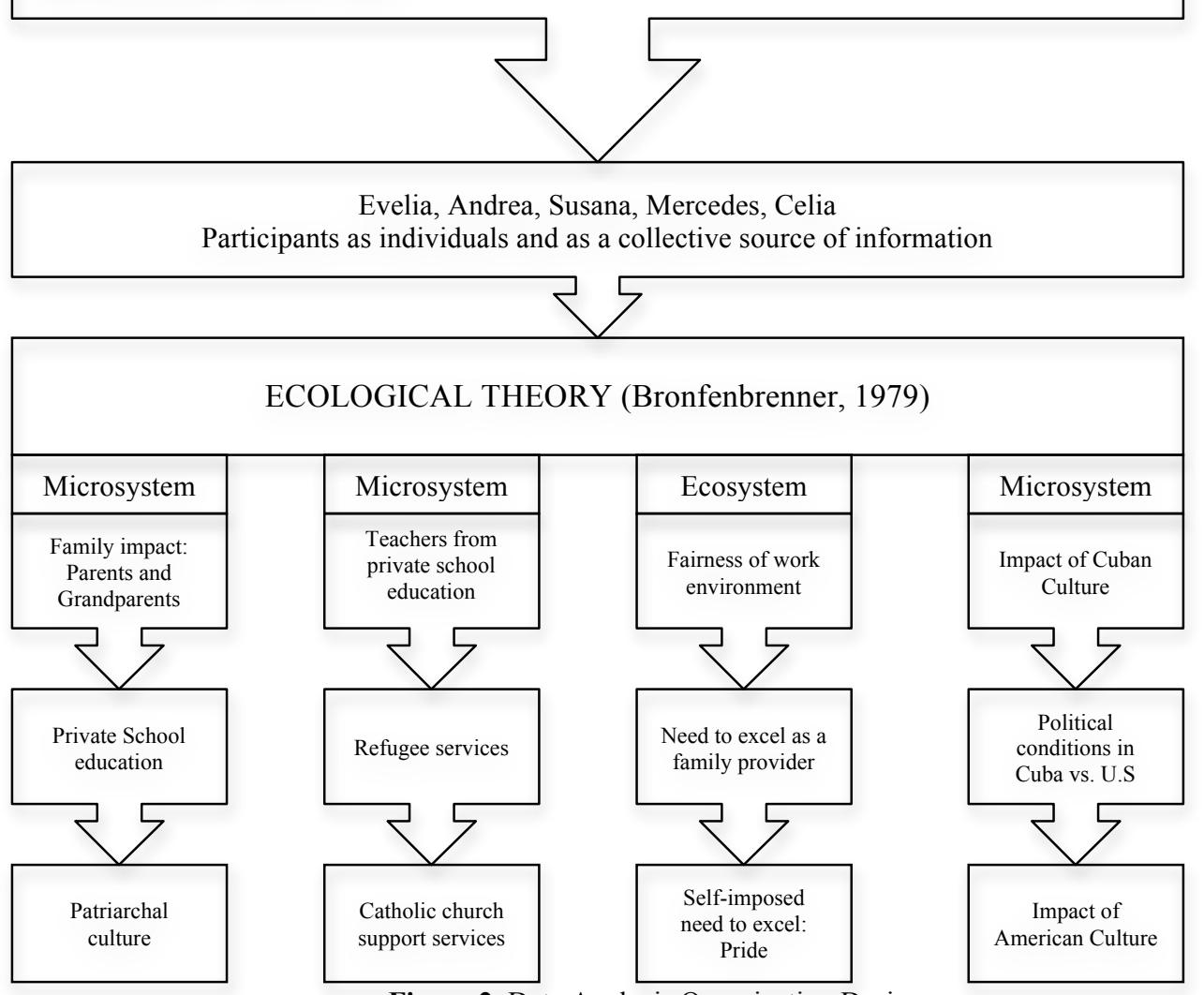

Figure 2. Data Analysis Organization Design

\section{Triangulation}

Qualitative research acknowledges that in qualitative studies everyone comes with biases. Therefore it is imperative for the researcher to set up a structured triangulation strategy to identify different perspectives and to ensure that the findings are not influenced by the bias of the researcher. The researchers solicited the assistance of five professionals from various backgrounds and areas of expertise to assist as peer reviewers.

The selection of the reviewers was strategically structured to ensure minimal biases: (a) three were professional in Cuban culture, (b) two were professionals in self-determination, (c) two were from a Hispanic background other than Cuban-America but professionals in fields other than self-determination, (d) two reviewer did not have any personal and professional ties to any of the areas of potential biases for this study. All materials were 
reviewed by each of the peer reviewers independently, and then discussed with the researcher. Notes on crossexamination and emergent themes were then discussed in small groups with two other peers. See Table $1-$ Peer Review Table.

Table 1. Peer Review Table

\begin{tabular}{lccccc}
\hline $\begin{array}{c}\text { Researcher } \\
\text { Potential Bias }\end{array}$ & Reviewer A & Reviewer B & Reviewer C & Reviewer D & Reviewer E \\
\hline $\begin{array}{l}\text { Hispanic Women in } \\
\text { Leadership Roles }\end{array}$ & & & H & H & \\
\hline Cuban Culture & CC & CC & & & CC \\
\hline SD & SD & SD & & & \\
\hline
\end{tabular}

Sample

The respondents were identified via a snowball sampling process. This sampling approach was used as it allows the researcher to choose participants based on their potential relevance and meaningfulness to the study (Bogdan \& Biklen, 1998).

The participation criteria for the study were as follows:

- Born in Cuba but have lived and worked in the US as result of their exile after Castro's rise in 1959

- Between the ages 45 to 72

- Achieved leadership positions

- Active or exited the workforce system recently

- Have a bachelor, masters, doctoral, and/or medical degree.

A qualitative phenomenological framework was selected for this study because this approach allows the researcher to be immersed in the research field to create and develop a trusting, ongoing relationship with the participants (Crouch \& McKenzie, 2006) to truly contemplate and address the research questions. According to the literature (Crouch \& McKenzie, 2006; Creswell, 1998; Morse, 1994), for this type of study, sample size should not be guided by how many participants the study has, but instead it should be guided by the concept of saturation. Creswell (1998) suggests that an adequate sample size for this type of study can be between 5 to 25 participants and Morse (1994).

In this study, 16 women were identified who met the criteria. Ten women indicated that they were willing to participate. After all the sources of data collected were thoroughly analyzed and triangulated, saturation of themes was reached at the fifth participant.

\section{Participants' Profiles}

The researcher included a brief profile of each individual to capture the essence of the information gathered for this study. These profiles showcase the voices of the participants as they shared comments about their lives. The profiles are divided into three sections: (a) social and demographic history, (b) educational and leadership growth and (c) self-determination. In order to protect participants' privacy, their names were changed. See Table 2 Participants' Profiles. 
Table 2. Participants Profile

\begin{tabular}{lccclcc}
\hline Name & Age & Gender & $\begin{array}{c}\text { Educational } \\
\text { Level }\end{array}$ & \multicolumn{1}{c}{ Job Status } & $\begin{array}{c}\text { County of } \\
\text { Heritage }\end{array}$ & $\begin{array}{c}\text { Residence } \\
\text { in Virgina }\end{array}$ \\
\hline Romona & 61 & F & Ph.D. \& M.D & $\begin{array}{l}\text { Medical Director } \\
\text { Family Clinics }\end{array}$ & Cuba & New York \\
\hline Evelia & 70 & F & M.A. & $\begin{array}{l}\text { Director } \\
\text { Charitable Organization }\end{array}$ & Cuba & $\begin{array}{c}\text { Southeast } \\
\text { Virginia }\end{array}$ \\
\hline Mercedes & 62 & F & Ph.D & $\begin{array}{l}\text { Higher Ed. Non-Profit Organization } \\
\text { Executive Director } \\
\text { Violence Intervention }\end{array}$ & Cuba & $\begin{array}{l}\text { Southeast } \\
\text { Virginia }\end{array}$ \\
\hline Susana & 57 & F & M.A & $\begin{array}{l}\text { Executive Director } \\
\text { Violence Intervention }\end{array}$ & Cuba & New York \\
\hline Andrea & 45 & F & B.A & $\begin{array}{l}\text { Founder and CEO } \\
70 \text { million Coproration }\end{array}$ & Cuba & $\begin{array}{l}\text { Northern } \\
\text { Virginia }\end{array}$ \\
\hline
\end{tabular}

\section{Ramona}

\section{Social and Demographic History}

Ramona has a very strong matriarchal aura about her. She is a charming 61-year-old woman who, along with her parents and two sisters, left Cuba in 1964 via Spain. Upon departure, Ramona's family, like everyone else, left all their wealth and possessions. Ramona was 15 years old when she arrived in Spain, and she attended a Catholic school on scholarship. At the age of 19, Ramona and her middle sister left for the United States, with the intention of bringing her parents and younger sister. Ramona did not know English when she arrived at age 19. She has a strong Catholic faith and is very proud of her Cuban blood: "I never forget where I come from...the hard work and heartaches; the sacrifices my parents endured to give me the freedom to be who I am today."

\section{Educational and Leadership History}

Ramona enjoyed a private Catholic education both in Cuba and in Spain. With a Bachelor of Science, she eventually earned a Ph.D. in Religious Studies from Fordham University in New York and an M.D. from the Ponce Puerto Rico School of Medicine. Ramona worked as a medical doctor in New York City for 35 years. She served for 12 years as president and medical director of a medical group, and was also medical director at two free clinics for the uninsured. She is actively involved in recruiting volunteer physicians and in guiding medical student volunteers in developing policy and procedures for these clinics. She has mentored hundreds of young medical doctors, and places a specific emphasis on supporting Hispanics through the educational pipeline. In addition, she has a long history of working in her community, including running several free clinics and soup kitchens. She has a long history in providing help to poor immigrants, and she has been honored with various awards for her exemplary dedication to her community. She explains that "[when] growing up, education and excelling in life was not a choice; it was my family's expectation...giving back to others is what I was taught to do from a very early age."

\section{Self-Determination}

During the interviews, it became evident that Ramona's father has been the most influential figure in her life. In her words, her father was a very kind, strong, and determined person who was a fearless mentor to his family and to other Cubans in his exile community. Illustrative of his role and influence in her life, she emphatically states, "I am my father's daughter!" Her personal values include excellence, hard work, justice, and respect.

\section{Evelia}

Social and Demographic History

Evelia is an elegant and soft-spoken 72-year-old woman born in Havana, Cuba. She has lived and worked in Virginia for many years. Evelia is an only child and left Cuba with her mother and father in 1968 via Spain. After 
living in Spain for 5 years, she and her family moved to the United States. According to Evelia, she came to the United States with her parents in pursuit of freedom and opportunities. She stresses that her parents left Cuba with the desire to give her the opportunity to have a future in a free country; a future that would offer her choices, choices, which they thought, would always be available in Cuba, but were no longer available. Evelia lives a very altruistic life. Aside from her professional career and a family of three, she has an extensive history of dedicated service to community programs designed to help under-privileged immigrant families. Evelia is a very active member of her community and is very proud of both her American citizenship as well as of her Cuban heritage. Reflecting on her Cuban heritage, she shared: "I'm a very determined person with strong values of excellence and drive to excel in life, and this stems basically from my Cuban heritage...my parents and grandparents."

\section{Educational and Leadership History}

Evelia was in her twenties when she left her native country. During her early education in Cuba, preCastro, she attended private schools and completed a degree in Engineering before leaving Cuba. Her educational background is balanced between the arts and science. Once in the United States she continued her education, but was never able to validate her engineering degree to be able to exercise her career in that field. She now works for a community-focused organization. Evelia shared that her frustration not being able to work in her field drove her to work harder to help others with similar experiences. Her sense of justice inspired her to lead numerous social programs in the area of immigration.

\section{Self-Determination}

Evelia's self-determination was evident throughout the information gathered about her and from her. During the interviews and during the observations, Evelia was very assertive in a very unique way. She was calmed, soft-spoken but very firm in her convictions and values. During the interview, she stated that she made her decisions on her own but that she always tried to follow her family's advice. Specifically, she says: "still at my age I remember my parents' voice telling me to strive for excellence and live my life with pride...my family is intense and very determined when it comes to education...we must have an education - it is not a choice - it is a responsibility."

\section{Mercedes}

\section{Social and Demographic History}

Mercedes is a petite woman, with a strong, yet calm demeanor. She speaks about others with a firm sense of responsibility. She understands the road that must be traveled and wishes to guide others toward a better and more educated life. Her voice resonates a matriarchal tone: "I am here for you, do right, work hard, be proud...make me proud."

A native of Santiago de Cuba, Mercedes was 14 years old when she arrived in the United States. Mercedes lost her father at an early age. She is an only daughter, with a much older brother who took over the role of father once they both arrived in the United States. "I was spoiled and was daddy's girl, with my maternal grandfather being a strong role model and my older brother my guardian angel." PreCastro, her socioeconomic status could have been described as high, and education was very important even to her parents' generation. Family values concentrated on excellence, education, pride, and honor to the family and, in exile, to the homeland. Mercedes shared that she is still angry at having to leave her home and family.

\section{Educational and Leadership History}

Mercedes explains that she had no knowledge of English upon her arrival. A private scholarship, part-time jobs, and the Federal Cuban Student Loan program at a Catholic women's college funded her Bachelor of Arts. Her Master's and Doctoral degrees are from American University in Washington, DC. Her leadership role in society is extensive within the Hispanic community, and her work emphasizes promoting higher education for Hispanics. She defines herself as a "Servant Leader" and shared that what she does as a leader emerges from what is valuable to her, i.e., a sense of giving back to the community. Mercedes called it "pay back." 


\section{Self-Determination}

Mercedes explains that though she always had a strong-willed and determined disposition, exile forced her to enhance her self-determination skills. She says: "In exile I needed to develop my self-determination skills to survive...exile makes you grow up fast." Mercedes's self-determination is clearly defined by her experience as an "exile" and is fueled by pride in her Cuban heritage. She explains that exile has made her a more aggressive and assertive person, who is often angered and distressed by the injustices she sees around her. "Living life in exilesomeone perceived initially as a 'nobody' who had to 'make it' and become 'somebody,' augmented my pride for my heritage...that pride helped to preserve my dignity."

\section{Susana}

Social and Demographic History

Susana, the oldest of five sisters, left Cuba in 1960, at the age of 12. With her parents and five sisters, she went from Cuba to Mexico, living there for a year before settling in Louisiana and then, finally, Virginia. After her marriage, Susana travelled extensively and she currently lives in New York. When asked about significant role models in her life, Susana indicates that her father and grandfather are her most significant role models but that her father's values were highly influenced by his mother's values of social consciousness. When talking about Cuba and the home she will never be able to go back to live in, she shared: "exile marks you as person without motherland...for me home is where I make it."

\section{Educational and leadership History}

Susana was educated in Catholic private schools, both in Cuba and in the U.S. Parental expectations for her and her four sisters included getting an education, playing sports and taking initiatives on social justice causes. "We were raised to be problem solvers and were constantly challenged to be critical thinkers, and our values included education says Susana of her upbringing. She emphasis: "as Cubans we lost everything but not our values and education." Her father is a Harvard architect, and although her mother does not have a college degree, she is fluent in three languages: Spanish, English and French. Susana has a Masters in Social Services from New York University. "My cause is social justice for women", states Susana, who is the CEO of a center that supports abused women, in New York. With a collaborative leadership style at work, Susana says that "she is not afraid to ask for help", feeling that she needs to be available to those who work for her and with her.

\section{Self-Determination.}

"I am a very self-determined person...I never saw myself as a leader, however others do. I only do what in my heart I know I have to do." Susana's inclination towards social justice causes came from her father, who learned it from his mother. All her life she was taught that education was not a choice, that it was a way to be a better person. She indeed, feels a certain pressure to live a life of self-determination, leadership and altruism. "It's a skill that we were taught...we were taught and lead by example and I must do the same." In this life taught and led by example, Susana's personal and business values are driven by excellence, justice.

\section{Andrea}

\section{Social and Demographic History}

Andrea is a 45-year-old energetic and eloquent woman. Born in Havana, Cuba, Andrea left as a toddler along with her sister, parents, and grandparents. They went to Miami, where her parents still reside. English and Spanish are spoken in her home, but she will still interpret for her parents. She left Miami and currently lives in Northern Virginia, where she is the CEO and founder of a multi-million dollar corporation. Andrea is very proud of her Cuban heritage, even though she sees herself as an American. She recalls with sorrow how she, at an early age, had to play two roles: daughter and parent to her parents, as she had to translate and help her parents adjust to the new country and culture. 
Andrea makes it clear she will never forget her roots or how hard her parents had to work to make a life in the United States. She recalls how emotionally difficult it was for her to see her parents work so hard; how people did not value her parents because they did not speak English; and how painful it was for her to see how Americans underestimated who they were because they were immigrants. Andrea recalls moments as she was growing up where she swore to herself that she would one day show the world what a strong determined Cuban could do for this country. In her words: "I remember feeling so frustrated and angry at the humiliations my father had to go through and thinking to myself 'fuck them!' one day I will show the world what we, Cuban immigrants, are capable of doing." Andrea has a great sense of responsibility for her whole family; in her words: "I need to take care of my family."

\section{Educational and Leadership History}

In her youth, Andrea attended school in Miami. She moved to Washington, DC, in her twenties, where she completed a Bachelor of Science at George Washington University. Soon thereafter, she founded her company. Her determination to pursue higher education came from her parents who, after losing all their properties (e.g., home, car, personal and financial assets), when they fled Cuba, firmly required their daughter to obtain an education. According to Andrea, her parents always told her: "You can lose everything in life, but no one can take away your education."

Andrea's passion in life is justice; justice for all...in her own home and in the community at large. In her own words: "The business world needs Hispanic women with 'chispa' [drive]; women who understand the importance of discipline, compassion, family, and community."

\section{Self-Determination}

Andrea is a very passionate and determined woman who has many dreams and strong ambition. She wants to "live and love with passion, and she wants to work and support others with passion." She shares that her company's values are very similar to her own personal values; excellence, reputation, responsibility, drive, and a desire for a better future.

"My family (including my grandmother) and extended family are my role models: working hard, unconditional love, and support for all." Andrea also shared her perspective on Cuban-American women: "We Cuban women have 'drive;' we are individuals who understand the importance of discipline, compassion, family, and community." And as for her remarks on what she considered to be her success as a leader, she remarked: "Truly successful businesses are built from the heart and the soul of great leaders. I became a leader out of struggle, and exile has definitely defined who I am: strong, determined, compassionate, and proud!"

\section{THEMES}

Two major themes emerged: self-determination and values. Within the values four categories were identified (a) family strength and support; (b) pride in heritage ;(c) value of education; and (d) pay it forward: mother of all.

These individuals described a process for making choices and decisions for their lives that included most of the core components of self-determination (.e. choice-making, goal setting and attainment, self-knowledge, etc.).They also engaged in a problem-solving process that included: identifying the problem; identifying possible solutions; describing the possible consequences for each solution; choosing the best option; implementing the chosen solution; and finally, evaluating the outcome. What was unique about the self-determination skills described by the participants is that family played a central role in the goals they chose, impacted their cultural values, and influenced their need/desire to care for others. 


\section{Findings by Self-Determination Theory}

It was very apparent that these women made life choices and decisions that were free from unwanted influence. However, the majority of their decisions were directly influenced by their family and Cuban cultural values as these factors proved to be an integral part of who they are as individuals.

\section{Values}

A second theme that emerged from the data collected for this study is the cultural value of family strength and support and the value placed on education.

\section{Family Strength and Support}

The families of the women in this study can be described as interconnected and close-knit. Through their answers, they described frequent family dinners, celebrations, and staying touch with family regardless of geographical separation. Many of them stated that even though their family members are located all over the world, they would make themselves available to help or to listen whenever in need. Most participants spoke about the need to consult with each other on a regular basis, as well as to share the small and large occurrences in their lives. While it was clear that these women made their own decisions, they ultimately felt a sense of comfort when consulting with their family. This consultation was not viewed as unwanted or a barrier to their decision-making, rather, as a necessary and valuable part of the process. Family members consulted and included in this process extended beyond the immediate nuclear family; it included aunts, uncles, cousins, and grandparents. In many cases, other individuals who were not directly related by blood but by culture were consulted.

It was observed that both the respondents and their parents sought each other for consultation and reassurances. Parents, being immigrants to a new country, would often look up to their daughters as the "leading figure," placing significant responsibility and trust on their daughters to make the right decisions for their family. It is very clear from the collected data that any decisions made by the respondents were meant to encompass and preserve the values of the family. By playing the parental role for their parents, the respondents obtained a great sense of responsibility and developed into a leadership position in their family.

\section{Pride in Heritage}

Pride in heritage is a recurring theme that was subconsciously revealed by the participants. The "pride for Cuban heritage" that emerged is not necessarily pride for the "Mother Land;" instead, it is the essence of what their roots mean to them - roots of social consciousness (including freedom), and pride for self. These two powerful socially inherited values are part of the participants' intrinsic identities.

Participants' narratives tell of a Cuba in which they grew up and the moral values with which their parents raised them. These include (a) appreciation for the arts (music, art, dance, writing), (b) education as a means to develop into a better person, (c) freedom (i.e., free enterprise, and freedom of speech), and (d) pride in hard work.

\section{Value of Education}

Ramona said, "My parents left Cuba to ensure that we [my sisters and I] were free to receive the best education possible...we have to have an education - it is not a choice - it is a responsibility."

For these women and their parents, the value of receiving an education extended well beyond high school. All respondents have either a master's, doctoral, and/or medical degree. Andrea, at age 45, is going back to Harvard to pursue her master's and plans to continue on to a doctoral program. Mercedes has a Ph.D. and several education certifications and licensures. Ramona, at age 35, has already completed both an M.D. and a Ph.D.

When asked what motivated the participants to obtain higher education degrees, they all expressed the primary factor as self-determination. However, it became apparent that what drives their strong self-determination is 
intrinsically motivated by their family and past experiences. For example, a theme that emerged when speaking to all respondents was that education is something that cannot be taken way; it is a value that stays with a person forever. Each participant stated the same value - "we never lose our education."

\section{Pay it Forward: Mother of All}

Another overarching theme was a sense of responsibility to help others. Through each one of the participants' work, despite the field (medical, social services, business, education, the arts, etc.), they all give back to their families and to society. Each of the women conveyed the same sentiment:

"I need to take care of my family."- Andrea

"I am a servant leader; my leadership style emerges from what is valuable to me and from a sense of giving back what once I received from others." - Mercedes

"Giving back to others is what I was taught to do from a very early age..." - Ramona

\section{Findings by Ecological Systems}

The findings from the analysis of the four ecological system levels revealed significant influence from the Microsystem and the Macrosystem.

Regarding the Microsystem, the data reveal that their families and extended families primarily influenced the majority of the women's experiences in their preparation for adulthood and entrance into the workforce. Further, each woman was strongly influenced by father figures, whether it was their father, grandfather, or brother, and they viewed these figures as fighters or leaders within their community. Through these father figures, each woman developed a sense of "self." All the women in this study are daughters who were empowered by their heroes to be leaders and act in a patriarchal way.

The majority of the participants came to the United States with an educational mindset based in pride and excellence. Despite economic and social challenges, these women, on their own or with family support, continued to aggressively seek higher education. Only one participant, Andrea, did not receive a private education in the United States. However, her education was supplemented by her family's strong ties to their cultural values of excellence and hard work.

At a very early age these women were encouraged to be inquisitive, problem solvers, independent, and to see education as a means for personal and professional development. Education was a means to be a better person, to acquire the quality of life they sought, and to help themselves and their families succeed. Therefore, the data support the premise that education and family values had a strong influence on each participant.

The second strongest influence is the Macrosystem; the interaction with the larger cultural context which influences all the other systems. For this particular group of women, the Macrosystem includes experiencing the drastic change between the political philosophies of a free Cuba versus a communist Cuba. Each woman experienced the dramatic change of a country where citizens were stripped of their economic and social status, their freedom to maintain their family's life style, the right to make choices, and even the right to worship. The sharp juxtaposition of values from one regime to another deeply affected the Cuban culture and particularly these women.

Exile was another strong influence in shaping the participants' self-determination. They wanted to simply transplant their family and their values to a new country. As they were forced to leave so much behind, it became a goal in each family to secure their own cultural and economic place in their new homeland.

Participants' stories and the analysis of the data show that they were able to fulfill their family's hopes and dreams. In Mercedes' words: "Living life as an exile - someone perceived initially as a 'nobody' who had to 'make it' and become 'somebody,' augmented my pride for my heritage... that pride helped to preserve my dignity." 


\section{SUMMARY OF FINDINGS}

The cross examination of the major themes that emerged from the data across the four systems validates the themes from the cross-examination of all the other data that were collected, adding validity and reliability to the findings. It inferred the assumption that the role of self-determination for Cuban-American females in leadership roles is shaped and influenced by their families' values, culture, and expatriation. These women showed that their family held education, personal growth, and self-determination as high values and priorities. Ramona remembers her father always telling her: "Your determination and dedication will make it happen." She adds, "For me, failure is not an option." The respondents also reported that the greatest motivation to continue their education was their family's high expectations and unconditional support as well as their own sense of responsibility toward their family. Ultimately, respondents' family and cultural values appeared to motivate them to plan for the future.

\section{Limitations of the Study}

This study was an initial exploratory study with a small sample size appropriate for a qualitative study. Sample size was purposefully limited to a small number of cases to allow for an in-depth collection of information per participant. Though only five cases were studied copious data was collected from over four different sources. Cross-examination and triangulation of the data served to protect the validity and reliability of the findings. Further systematic empirical investigation is recommended hoping the numbers will yield an unbiased result that can be generalized to a larger sample size.

\section{CONCLUSION}

This study provides insight into the role of self-determination for postCastro Cuban-American women in leadership roles in the United States. It provides a description of the many dynamics and social influences that can shape, guide, and support their self-determination skills. It also gives insight into the culture, values, capital, and experience of Cuban-American women and their drive to lead.

Additionally, a unique pattern surfaces from the findings on the role and affect that self-determination had in how this particular group of women became leaders. In a society devoid of perceived gender obstacles, the women in this study became societal leaders. Self-determination was the prevailing trait attributed by all respondents to achieving their success. What is even more revealing is that for these women, self-determination stems from their passion, determination, and sense of responsibility to care and support others.

\section{AUTHOR INFORMATION}

Dr. Elin Cortijo-Doval holds a baccalaureate degree in Art and Design from La Roche College; a master and a doctorate in Education from Virginia Commonwealth University. She has twenty-year of experience in organizational leadership and management within her own company and the community at large. Dr. Cortijo-Doval's research areas include leadership, self-determination \& empowerment, pedagogy and diversity. She teaches Organization and Management, International Business and Organizational Behavior. Dr. Cortijo-Doval is also the Associate Director of the Yale University Sherwin B. Nuland Summer Institute in Bioethics. E-mail: edoval@vsu.edu

Professor Doval holds a Juris Doctorate from Syracuse University College of Law and a Masters of Science in Telecommunications, Security and Network Management from Syracuse University School of Information Studies. Professor Doval's research areas include business law, ethics, intellectual property and pedagogy. He teaches Business Law, Business Ethics and Corporate Sustainability. E-mail: cdoval@vsu.edu (corresponding author)

Dr. Mirta M. Martin is the ninth president of Fort Hays State University. Dr. Martin holds a baccalaureate degree in psychology and political science from Duke University; a master of business administration degree from the University of Richmond; and a doctorate with an emphasis in strategic management and leadership from Virginia Commonwealth University. Dr. Martin's career involves work in both the public and private sectors, including special expertise in organizational behavior, management, institutional advancement and workforce development. E- 
mail:m3martin@fhsu.edu

Maricel Quintana-Baker, PhD. At $M Q B$-Consulting, she specializes in research and program evaluation, higher education policy, Latinos, Latinos and STEM, and cultural competencies. Previously she served as Associate Director for Academic Affairs and Planning at the State Council of Higher Education for Virginia (SCHEV); and on the Council on the Status of Women and the Virginia Latino Advisory Board. She is a member of the National Advisory Board for the Computing Alliance of Hispanic Serving Institutions (CAHSI), and worked as an ORISE Post-Doctoral Fellow at NSF. She holds a Ph.D. and M.A. from American University and is originally from Santiago, Cuba. E-mail: maricelqb@gmail.com

Don Anque is the author of several publications ranging from legal pedagogy to environmental policy. His scholarship work has been featured with various universities around the country, including Temple University, the University of California, and the Harvard Journal of Hispanic Policy. Anque received his J.D. from Syracuse University and his B.A. in English from UCR. While at Syracuse, he earned a Segal AmeriCorps Education Award and a certificate in National Security and Counterterrorism. For UCR, Anque was awarded a full ride grant from the California Department of Veterans Affairs and was the primary investor for the ASUCR Biodiesel Program. E-mail: don.anque@gmail.com

\section{REFERENCES}

Abery, B. H., (Nov., 2000). Self-Determination: A critical aspect of educational experience. Paper presented at the State of Hawaii Department of Human Services Self-Determination Conference. Honolulu, HI.

Abery, B. H., Stancliffe, R. J., (1996). The ecology of self-determination. In D. J. Sands \& M. L. Wehmeyer (Eds.), Self-determination across the life span: Independence and choice for people with disabilities (pp. 111-145). Baltimore: Paul H. Brookes.

Abery, B. H., Stancliffe, R. J., Smith, J., McGrew, K., \& Eggebeen, A. (1995a). Minnesota opportunities and exercise of self-determination scale-adult edition. Minneapolis, MN: University of Minnesota, Institute on Community Integration.

Bandura, A. (1986) Social foundation of thought and action: A social cognitive theory. Englewood Cliffs, NJ: Prentice-Hall.

Bean, F. D., \& Tienda, M. (1987) The Hispanic Population of the United States. New York: Sage.

Bogdan, R. C., \& Biklen, S. K. (1998). Qualitative research for education: An introduction to theory and methods (3rd ed.). Boston: Allyn \& Bacon.

Boone, Margaret S. (1980). The uses of traditional concepts in the development of new urban roles: Cuban women in the US. In E. Bourguignon (Ed.), World of Women: Anthropological Studies of Women in the Societies of the World (pp. 235-270). New York: Praeger.

Boone, Margaret S. (1989). Capital Cubans: Refugee adaptation in Washington, D.C. New York: AMS Press.

Bronfenbrenner, U. (1979). The ecology of human development: Experiments by nature and design. Cambridge, MA: Harvard University Press.

Bronfenbrenner, U. (1989). Ecological systems theory. Annals of Child Development, 6, 187-249.

Creswell, J. W. (1998). Qualitative inquiry and research design: Choosing among five designs. Thousand Oaks, CA: Sage.

Crouch, M., \& McKenzie, H. (2006). The logic of small samples in interview-based qualitative research. Social Science Information, 45: 483.

Deci, E. L. \& Ryan, R. (1985). Intrinsic motivation and self-determination in human behavior. New York: Plenum Press.

Deci, E. L., \& Ryan, R. M. (2000). The 'what' and 'why' of goal pursuits: Human needs and the self-determination of behavior. Psychological Inquiry, 11, 227-268.

Deci, E. L., Eghrari, H., Patrick, B. C., \& Leone, D. R. (1994). Facilitating internalization: The self-determination theory perspective. Journal of Personality, 62, 119-142.

Fernandez, D. J. (Ed.). (1992). Cuban Studies Since the Revolution. Gainesville, FL: University Press of Florida.

Garcia, M., C. (1997). Havana USA. Berkeley, CA: University of California Press.

Garcia, M. C. (Spring 1991). Adapting to exile: Cuban women in the United States. Latino Studies Journal, 2,17-33.

McMillan, J. H., \& Schumacher, S. (2006). Research in education: Evidence-based inquiry (6th ed.). Pearson. 
Morse, J. (1994) Emerging from the data: The cognitive processes of analysis in cognitive inquiry. In J. Morse (ed.) Critical Issues in Qualitative Research, 22-43. Thousand Oaks, CA: Sage.

Parahoo, K. (1997). Nursing research. Principles, process and issues. London, Macmillan.

Patton, M. Q. (1990). Qualitative evaluation and research methods ( 2nd ed.). Newbury Park, CA: Sage.

Prieto, Y. (1984). Cuban Women in the US Labor Force: Perspectives on the Nature of Change. Dissertation Abstracts International, 46(3), 804A.

Prieto, Y. (1987). Reinterpreting an immigration success story: Cuban women, work, and change. In Cuban Studies/Estudios Cubanos 1,7 73-91. Pittsburg, PA: University of Pittsburgh Press.

Safa, H. I. (1995). The Myth of the Male Breadwinner. Boulder, CO: Westview Press.

Taylor, S. J., \& Bogdan, R. (1998). Introduction to qualitative research methods. (3rd ed.). New York: Wiley.

Trainor, A. A. (2005). Self-determination perceptions and behaviors of diverse students with LD during the transition planning process. Journal of Learning Disabilities, 38(3), 233-249.

Van Manen, M. (1990). Researching lived experiences. New York: State of New York Press.

Wachs, T. D. (2000). Necessary but not sufficient. The respective roles of single and multiple influences on individual development. Washington, DC: American Psychological Association.

Wehmeyer, M. L., Abery, B. H., Mithaug, D. E., \& Stancliffe. (2003). Theory of self- determination: Foundations for educational practice. Charles C. Thomas. 


\section{Interview Protocol}

\section{APPENDIX}

Personal Information: Age:

Year you left Cuba:

Do you have siblings? Did you leave Cuba with your Siblings:

Did you leave Cuba with your family?

Explain:

Age when you came to the U.S:

City/Province of Cuba where you where born:

Did you come to the U.S. right after leaving Cuba?

Expalin:

Years living in the U.S.:

Where in the U.S.:

Where you fluent in English when you came to the U.S?

Let's talk about you and how you make employment/career and some personal decisions:

1. Tell me, how you make your decisions about what career/job you want?

a. Possible probes/rephrases: Give an example, do you consult with others; follow advice of others, family members, professionals?

2. Tell me, what factors do you take into consideration when making decisions about your career/job, what influences you?

a. Possible probes/rephrases: give me an example; do you take into consideration your family's input, your own beliefs and desires, cultural expectations?

3. Tell me, how do you make plans about where you want to work, how you want to work, and/or who do you want to work with, what influences you?

a. Possible probes/rephrases: Give an example, how do you make plans for where you are going, what you are going to do during the weekend, etc?

4. Tell me, how do you follow-up on decisions you make about work related training and responsibilities?

a. Possible probes/rephrases: Give me an example; do you follow-up independently, with help from friends or family members, technology?

5. How would you characterize the development of your leadership capacity?

a. Possible probes/rephrases: Were you a naturally born leader? Was it a struggle? Did something spur you in to that role?

6. Describe your leadership/management style. What purpose does it serve and what influences are behind it? a. Possible probes/rephrases: Macro, Micro...?

7. Do you experience pressure from either internal or external sources as to how you ought to perform? What are they? How do they drive you?

a. Possible probes/rephrases: Ancestry? Religious? Familial? Personal conviction?

8. Tell me, how does your Cuban background (religion, language spoken at home, family values, and traditions) impacts in your efforts to accomplish what they set out to achieve?

a. Possible probes/rephrases: Give me an example of how it helps, facilitates or impedes. Do you select career choices that your family considers a tradition in your family/culture?

9. Any comments you would like to add? 